\title{
THE DIAGNOSIS, EPIDEMIOLOGY AND CONTROL OF URINARY INFECTION IN UROLOGY AND GYNAECOLOGY
}

\author{
BY \\ W. A. Gillespie, K. B. LINTON, A. MILlER, and N. SladE \\ From the Department of Pathology, United Bristol Hospitals, and the Departments of Urology, \\ United Bristol Hospitals and Southmead Hospital
}

(RECEIVED FOR PUBLICATION JANUARY 1, 1960)

In a study of the urine after urological operations, quantitative bacteriological criteria for the diagnosis of infection were determined.

The bacteria responsible for urinary infection after urological or gynaecological procedures sometimes came from the same patient, but more often came from other patients by cross-infection. The principal final route of entry was the urethra or the indwelling catheter lying in it. These findings led to the elaboration of methods of destroying bacteria in the urethra before operation, improving the disinfection of cystoscopes, and preventing the entry of bacteria via the indwelling catheter. Application of these methods reduced the incidence of infection after prostatectomy from $83 \%$ to $6 \%$, and after emergency bladder drainage for acute retention of urine from $73 \%$ to $10 \%$. A smaller improvement followed the introduction of closed bladder drainage after gynaecological operations.

Urinary infection is a common complication of operations on the bladder and prostate and of drainage by indwelling catheters. This paper deals with the diagnosis and epidemiology of the infections and summarizes the results of preventive measures, some of which have been described more fully elsewhere (Miller, Gillespie, Linton, Slade, and Mitchell, 1958; Miller, Linton, Gillespie, Slade, and Mitchell (1960).

Methods of preventing infection were studied in patients who had sterile urine on admission to hospital and were not given prophylactic antibiotics or chemotherapy. There were three groups of patients :

(1) Men admitted under the care of members of one urological team with beds in both hospitals, for prostatectomy by the transurethral or the retropubic method. (Patients with suprapubic or perineal drainage of the bladder were excluded.)

(2) Men with acute retention of urine, treated as emergencies by indwelling catheter.

(3) Women who had gynaecological operations necessitating continuous bladder drainage by indwelling catheter.

The clinical effects of urinary infection were studied also in some patients whose urine was already infected before prostatectomy or who were admitted to wards where special measures to prevent infection were not yet in use.

\section{Diagnosis}

Urine was generally cultured within one hour and never more than two hours after collection, except for some of the initial samples which were cultured after overnight storage in the refrigerator.

Males.-The urine was examined daily (except on Sundays), starting from the day before operation, or from the first urine withdrawn from patients with acute retention. Urine was always obtained at operation by means of a cystoscope or catheter. Except for the first specimens from acute retention cases, all were collected by one of the investigators.

Many patients, when confined to bed, were unable to co-operate in the collection of " mid-stream " urine. For the sake of uniformity, therefore, specimens were passed direct into sterile jars, without prior cleansing of the glans penis and without discarding the first flow. When possible, large volumes were collected, usually $100 \mathrm{ml}$. or more, so as to minimize the effect of contamination from the urethra. Urine from patients on continuous drainage was withdrawn from the tube (after disinfecting it with alcoholic iodine) by means of a sterile syringe and needle.

Females.-Catheter specimens were obtained at operation. Thereafter, urine was taken each day from the drainage tube, as described above, and, after the indwelling catheter was removed, several " midstream" specimens were collected by a modification of the method of Hart and Magee (1957), in which the vulva was cleansed with sterile saline instead of 
disinfectant. Also, catheter specimens were obtained when residual urine was drained from the bladder.

Laboratory Examination of Urine.-After mixing, $10 \mathrm{ml}$. was centrifuged, and wet and Gram-stained smears of deposit were examined. Standard loopfuls of uncentrifuged urine were inoculated on well-dried blood agar and MacConkey plates. The loop was kept vertical when withdrawn from the urine, and held approximately $1 / 150 \mathrm{ml}$. Six loopfuls were placed separately on each plate ; five were allowed to soak into the medium without spreading and the sixth was spread over the rest of the plate. After aerobic incubation for 24 hours at $37^{\circ} \mathrm{C}$., colonies were counted, if less than 50 per loopful. When the colonies were more numerous, that is, with counts of more than 7,500 per ml., the growth was recorded as "moderate" or "profuse."

The sensitivity of the bacteria to antibiotics and sulphonamide was determined by a disc method (Fairbrother, 1952) and by the method of Harper and Cawston (1945). Organisms were identified by appropriate cultural and biochemical methods. Fermentation tests with adonitol and inositol were used to distinguish Klebsiellae from Escherichiae (Talbot, Cunliffe, and Gower, 1957). Most strains of Staphylococcus aureus were phage-typed (Williams and Rippon, 1952), and many strains of Escherichia coli were typed by means of colicines (Linton, 1960).

Criteria of Infection.-Infection was diagnosed when two or more successive daily specimens of urine contained more than 3,000 bacteria per ml. Occassionally, a single specimen contained many bacteria, but subsequent specimens were normal. This did not constitute an infection; it sometimes happened soon after withdrawing the indwelling catheter from a prostatectomy patient whose urine had hitherto been sterile, the organisms apparently having multiplied locally in the clot and debris near the operation site.

The limit of 3,000 organisms per ml. was based on the results of culturing urine taken on the day before operation from 263 men whose urine taken by cystoscopy next day was found to be sterile. Of the pre-operative specimens, 138 gave no growth, 80 gave counts of between 1 and 750 colonies per ml., 39 yielded 750 to 3,000 colonies per ml. and in 21 of thes: the organism was Staphylococcus albus. Six specimens gave counts between 3,000 and 4,500 per ml., but in five the organism was Staph. albus.

The diagnostic limit of 3,000 organisms per ml. was slightly higher than that adopted by Sanford et al. (1956), who took 1,000 per $\mathrm{ml}$. as the upper limit for normal urine. Their observations, however, were based on carefully collected " mid-stream" specimens, less subject to contamination than those used in the present investigation. On the other hand, Kass (1956) suggested the much higher limit of 100,000 organ:sms per ml. ; but this was based on established infections. In the present investigation, an infection was considered to start when the responsible organisms first appeared in the urine, even if they were initially fewer than 3,000 per $\mathrm{ml}$. Although the organisms were often scanty at the beginning of an infection, their numbers increased greatly during the next few days and almost invariably soon exceeded the limit of 100,000 per ml. suggested by Kass.

Hitherto, the diagnosis of infection in women has been based on the same criteria as in men, but it is hoped later to adopt standards based on a current investigation of catheter and " mid-stream" specimens from women.

\section{Bacteriological Results}

Before special steps were taken to reduce the incidence of infection, the organisms most commonly isolated from the urine of male patients were (in order of frequency) coliform bacilli, Proteus, Staph. albus, Streptococcus faecalis, Pseudomonas pyocyanea, and Staph. aureus. Many of the infections resulted from crossinfection; this was shown by the antibiotic resistance of the bacteria, by the results of typing Esch. coli and Staph. aureus, and by the occurrence of several "runs" of infection after prostatectomy caused by particular organisms (Gillespie, 1956 ; Linton, 1960).

Nearly all the infections in women were caused by coliform bacilli, Proteus, or Str. faecalis, and many of the organisms were resistant to several antibiotics. Mixed infections were common in both sexes.

Other workers have found the Klebsiella species to be responsible for much of the cross-infection by coliform bacilli in urological wards (Ørskov, 1952, 1954,; Dutton and Ralston, 1957). These organisms appear to develop resistance to antibiotics more readily than Escherichiae (Talbot et al., 1957 ; Lattimer, Seneca, Zinsser, and Troc, 1959). The two groups of coliform bacilli isolated from infections in the Bristol Royal Infirmary showed a similar difference. Thus, of 41 Klebsiellae, $38(93 \%)$ were resistant to one or more of the drugs streptomycin, tetracycline, chloramphenicol, and sulphonamide, compared with only $23(29 \%)$ of the Escherichiae.

Most strains of Staph. aureus showed multiple antibiotic-resistance and were evidently similar to those responsible for wound infections in the same wards (Gillespie, Alder, Ayliffe, Bradbeer, and Wypkema, 1959).

Pyuria.-During the first two to three days after operation, the urine commonly contained a moderate number of pus cells, even in the absence of infection. At other times, sterile urine contained few pus cells, and the upper limit of normal for wet preparations was taken to be 15 cells per high-power field. More than this constituted pyuria. 
In the early stages of an infection, there was often no pyuria. But within a few days pus cells nearly always became numerous. Of 281 patients with infected urine (including a few who were infected on admission), 269 developed pyuria at some stage. Of the 12 who did not, six were infected by Staph. albus, four by Str. faecalis, and two had chronic infections caused by small-colony coliform bacilli which probably were less virulent than normal strains (Gillespie, 1952).

The relationship between the infecting organisms and the pyuria was investigated in urine infected by single strains (Table I). Staph. albus and Str. faecalis were less often accompanied by pus, and

TABLE I

INCIDENCE OF PYURIA WITH DIFFERENT ORGANISMS

\begin{tabular}{|c|c|c|}
\hline Organism & $\begin{array}{c}\text { No. of Specimens } \\
\text { of Urine Yielding } \\
\text { Pure Cultures }\end{array}$ & $\begin{array}{c}\text { Specimens } \\
\text { Showing Pyuria }\end{array}$ \\
\hline $\begin{array}{llll}\text { Staph. aureus } & \ldots & \ldots & \ldots \\
\text { Proteus sp. } & \ldots & \ldots & \ldots \\
\text { Coliform bacilli } & \ldots & \ldots \\
\text { Other Gram-negative } & \text { bacilli. . } \\
\text { Str. faecalis } & \ldots & \ldots & \ldots \\
\text { Staph. albus } & \ldots & \ldots & \ldots\end{array}$ & $\begin{array}{l}40 \\
47 \\
99 \\
67 \\
22 \\
80\end{array}$ & $\begin{array}{l}38(95 \%) \\
43(91 \%) \\
87(88 \%) \\
58(87 \%) \\
16(73 \%) \\
54(67.5 \%)\end{array}$ \\
\hline
\end{tabular}

probably were less pathogenic than the other organisms. Staph. albus is often present as a commensal in the normal urethra (Shackman and Messent, 1954). Sometimes, however, it causes a definite though clinically mild infection, with numerous cocci and pus cells in the urine. But it was often difficult to decide whether Staph. albus was playing a pathogenic role, and therefore infections by this organism were not counted in the present investigation.

\section{Incidence and Clinical Effects of Infection}

The great majority of patients developed urinary infection within a few days of operation or insertion of an indwelling catheter (Table II). There was no appreciable difference between the incidence of infection after prostatectomy by the transurethral and the retropubic methods, but bacteria appeared to invade the blood stream more

TABLE II

INCIDENCE OF URINARY INFECTION DURING CONTROL PERIODS IN PATIENTS WITH URINE STERILE ON ADMISSION TO HOSPITAL

\begin{tabular}{|c|c|c|}
\hline Treatment & $\begin{array}{l}\text { No. of } \\
\text { Patients }\end{array}$ & $\begin{array}{l}\text { Patients } \\
\text { Infected }\end{array}$ \\
\hline $\begin{array}{l}\text { Prostatectomy (transurethral and } \\
\text { retropubic) } \\
\text { Acute retention treated by indwell- } \\
\text { ing catheter } \\
\text { Gynaecological operations with } \\
\text { indwelling catheters } \quad . .\end{array}$ & $\begin{array}{l}89 \\
26 \\
41\end{array}$ & $\begin{array}{l}74(83 \%) \\
19(73 \%) \\
40(98 \%)\end{array}$ \\
\hline
\end{tabular}

readily after the transurethral procedure $(C$. $\mathbf{H}$. Talbot, personal communication). This difference was similar to that demonstrated by Grey (1955).

After prostatectomy, the infections usually lasted for at least three months and often for much longer; and, although as a rule not clinically severe, they usually caused pyrexia. An important minority of the patients suffered the serious, and sometimes fatal, consequences of acute pyelonephritis, septicaemia, and bacteriaemic shock. The removal of the indwelling catheter often precipitated a transient bacteriaemia (Miller et al., 1958; Slade, 1958).

Several authors have emphasized the danger of invasion of the blood stream by bacteria from the infected urinary tract (Scott, 1929; Waisbren, 1951 ; Hall and Gold, 1955 ; Spittel, Martin, and Nichols, 1956 ; Ezzo and Knight, 1957). Their warnings have been borne out by experience in the surgical wards of these hospitals, where serious consequences of cross-infection, particularly septicaemia, have been caused more often by urological infection than by the staphylococcal infection of wounds which has received much attention in recent years. Such complications can be avoided only by preventing urinary infection in all urological patients.

\section{Epidemiology}

Measures to prevent cross-infection should be based, if possible, on epidemiological knowledge. In practice it is usually easy to suggest many sources of the organisms responsible for a particular outbreak, and many routes by which they may have spread; but it is often difficult to decide which are important. Obvious faults in ward and theatre techniques, and in the use of antibiotics, should be remedied. But in a particular situation it is of primary importance to identify the principal sources and routes of infection, and to concentrate on dealing with them. It is not necessarily enough to apply remedies which have been successful in other circumstances.

In the present investigation, many sources and routes of spread were found. The organisms mostly came from other patients ; some came from the patient's own body (Gillespie, 1956 ; Linton, 1950). But there was one important feature common to all cases: the susceptible tissues, the bladder and prostatic bed, were situated deep in the body, and organisms generally could reach them only via the urethra. (This was different from staphylococcal cross-infection in general surgical and maternity units, where the susceptible tissues are mostly superficial and can be reached 
by the staphylococci in many different ways.) It thus appeared that urological infection could best be prevented by excluding bacteria from the urethra and indwelling catheter before, during, and after operation. Methods of prevention were first tested in the prostatectomy patients, and the lessons learned from them were applied to the others.

\section{Results of Precautions}

Infection after Prostatectomy.-Because the causative organisms could often be isolated from ward furniture, blankets, etc., but were difficult to find in the theatre, the infections were at first thought to be post-operative, caused by organisms entering through the drainage tube and indwelling catheter which was left in situ for two or three days. Open drainage was in routine use. The lower end of the tube often became heavily contaminated from dipping intermittently into the urine which collected in an open vessel by the bedside. It was considered that bacteria were carried up the tube, against the flow of urine, by air bubbles which frequently ascended in it. That this could happen was confirmed experimentally. Moreover, when blood clot obstructed the catheter it was washed out by means of a sterile bladder syringe, a procedure which is difficult to perform aseptically. It was also thought that infection might be caused by bacteria which proliferated in the excess of secretion which often collects between the urethral mucosa and the outside of the catheter. This possibility was also suggested by Kass and Schneiderman (1957). To investigate it, swabs were taken from the lower end of the urethra, during drainage, and the organisms which they yielded on culture were compared with those which later caused urinary infection. The results were inconclusive (Gillespie, 1956). But the subsequent discovery that post-operative infection could usually be prevent by excluding organisms from the lumen of the catheter showed that the " extra-catheter" route was not important.

The first preventive measure was brought into use in the Bristol Royal Infirmary in November, 1955 , by substituting closed drainage for open drainage. This made no difference to the incidence of infection. The apparatus was then modified to allow the bladder to be washed out without opening the system, but, despite this, more than half of the patients still became infected (Fig. 1). However, most of the infections now developed very soon after operation and were thought to originate in the theatre. Patients who escaped infection at operation usually remained uninfected afterwards, so long as the bladder was drained and irrigated by the closed aseptic method (Miller et al., 1958).

The obvious next step was to review techniques in the operating theatre. It was found that the resectoscopes and cystoscopes, which could not be boiled, were being "disinfected" (after washing and taking them apart) by immersion in flat dishes of mercury oxycyanide solution, which is a poor disinfectant. The horizontal position of the instrument during this treatment may sometimes have prevented the fluid from completely filling the interior. A mixed aqueous solution of chlorhexidine (" hibitane ") 1/5,000 and mercury oxycyanide $1 / 2,000$ was found to be a much better disinfectant than oxycyanide alone and slightly better than chlorhexidine alone (Miller et al., 1958). The use of this solution, which was kept in tall cylinders in which the instruments could be immersed vertically, was followed by a sharp fall of the infection rate, to about $20 \%$ (Fig. 1).

Most of the infections that still occurred were caused by bacteria with normal antibioticsensitivity patterns, some of which resembled strains isolated from the urethra before operation and were probably pushed into the bladder at operation. The next step, therefore, was to attempt to disinfect the urethra before operation. As soon as the patient was anaesthetized, 5-10 ml. of $1 / 2,000$ solution of chlorhexidine in glycerine was injected into the urethra and held there for about 10 minutes before operating. After this final precaution the incidence of infection fell again, to about $6 \%$ (Fig. 1).

Despite the greatly reduced incidence of infection following the introduction of the combined precautions, the value of closed drainage and irrigation was still in some doubt. The work was therefore repeated in Southmead Hospital, where the basic techniques were the same as those formerly in use in the Infirmary. Similar precautions were introduced, but in a different order. First, both of the "theatre precautions" were introduced simultaneously (the disinfection of the urethra and the disinfection of cystoscopes by means of chlorhexidine without oxycyanide). The resulting small improvement was similar to that which had followed the post-operative precautions at the other hospital. But the subsequent addition of closed drainage and irrigation brought about a marked improvement (Fig. 2), almost identical with that finally achieved in the Infirmary.

These results showed that each of the precautions was important, but that a substantial improvement could be achieved only by using 


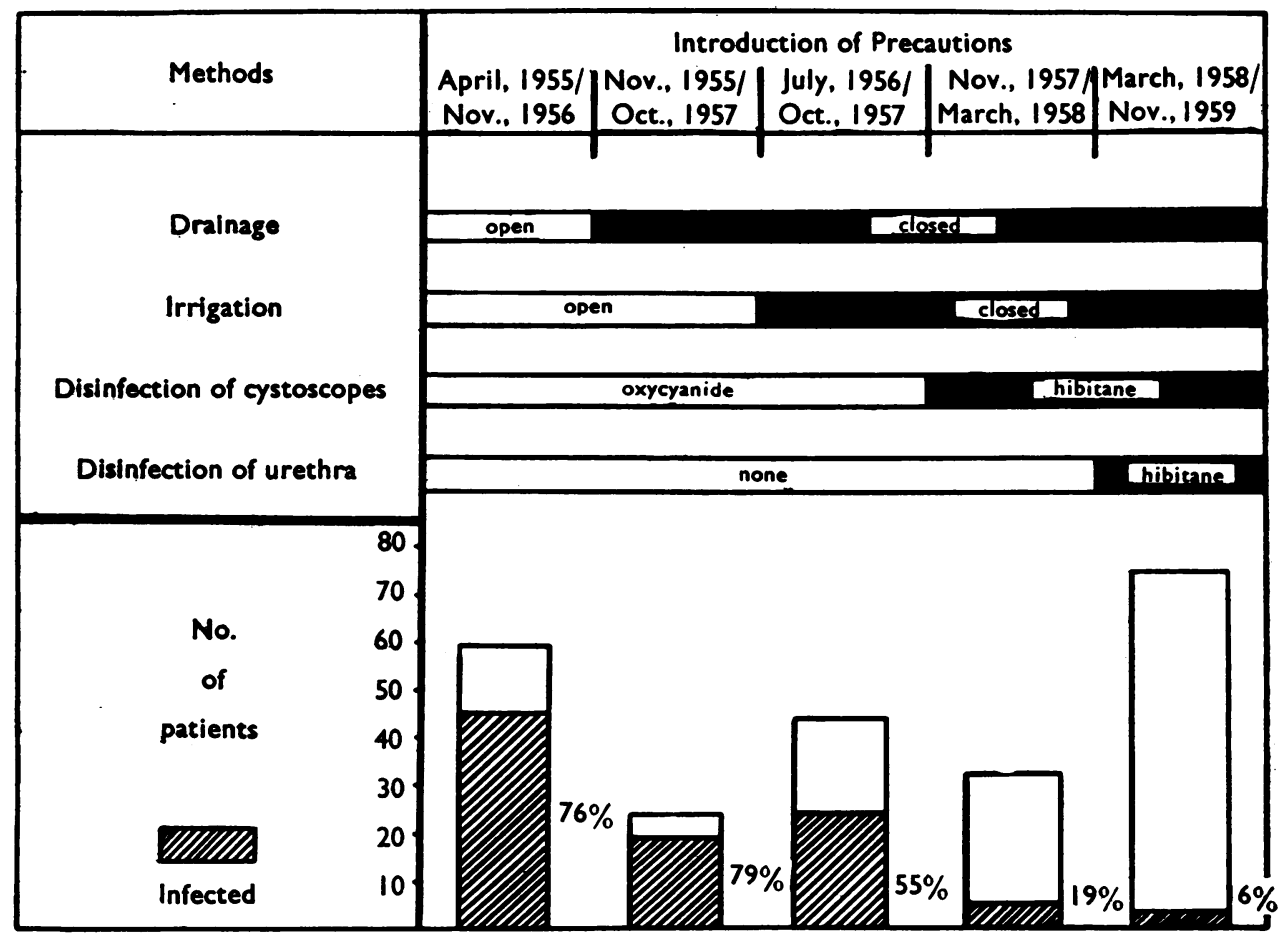

FIG. 1.-Effect of extra precautions on the incidence of urinary infection after prostatectomy in the Royal Infirmary.

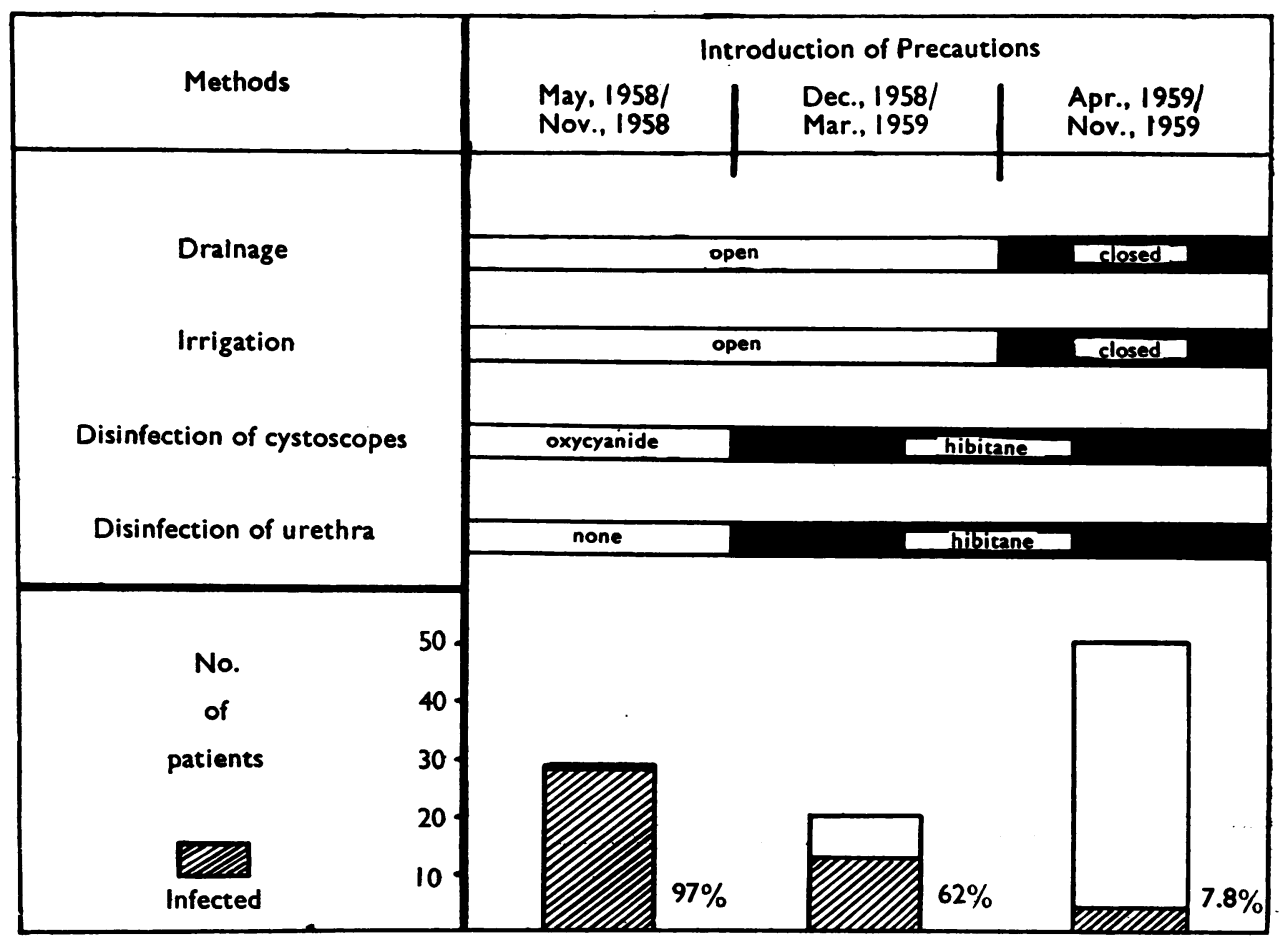

FIG. 2. -The effect of extra precautions on the incidence of urinary infection after prostatectomy in Southmead Hospital. 
them in combination, when the incidence of infection in the two units fell to about $6 \%$ compared with more than $80 \%$ formerly (Table III).

In about $10 \%$ of the patients, the closed drainage system failed, usually because of profuse bleeding. Unless such patients were watched constantly, and frequently irrigated in the first hour or two after operation, their catheters often became so firmly blocked by clot that no method of irrigation was effective. The drainage apparatus then had to be dismantled, a new catheter inserted, and infection usually followed. These cases presented a surgical rather than a bacteriological problem, and showed the importance of haemostasis.

The overall infection rate among patients who were put on full precautions, including those whose closed drainage failed, was $12 \%$ (Table III). None developed septicaemia or bacteriaemic shock.

TABLE III

SUMMARY OF RESULTS WITH PROSTATECTOMY

\begin{tabular}{|c|c|c|c|}
\hline \multirow{2}{*}{\multicolumn{2}{|c|}{ Hospital }} & \multicolumn{2}{|c|}{ Infections/Total Patients } \\
\hline & & $\begin{array}{l}\text { With No Additional } \\
\text { Precautions }\end{array}$ & $\begin{array}{l}\text { With Full } \\
\text { Precautions }\end{array}$ \\
\hline $\begin{array}{l}\text { Infirmary . } \\
\text { Southmead }\end{array}$ & $\begin{array}{l}\cdots \\
\cdots\end{array}$ & $\begin{array}{l}45 / 59(76 \%) \\
29 / 30(97 \%)\end{array}$ & $\begin{array}{c}475(5.3 \%) \\
4 / 51(7.8 \%) \\
\text { Results when closed drain- } \\
\text { age failed because of } \\
\text { excessive bleeding } \\
8 / 12(67 \%)\end{array}$ \\
\hline Totals & .. & $74 / 89(83 \%)$ & $16138(11.6 \%)$ \\
\hline
\end{tabular}

The importance of blood-stream infection as a complication of urological procedures was brought out by an analysis of all the cases of bacteriaemia and septicaemia which were diagnosed by blood culture in the Bristol Royal Infirmary during the year ending October 31,1959 . Of the total of 33 cases, $12(36 \%)$ were complications of operations on the urethra or bladder, or of the passage of sounds. None of these 12 patients had been treated with the full precautions described above ; many already had urinary infections before they came to operation. The organisms isolated from their blood were coliform bacilli (four cases), Proteus sp. (three), Staph. aureus (two), Ps. pyocyanea (one), Str. faecalis (one), and Staph. albus (one). In every case, a similar organism was isolated from the urine. Four strains were abnormally resistant to antibiotics. Although many of the patients already had infected urine before operation, in at least 10 cases the organisms invading the blood stream were newcomers which had infected the urine since admission to hospital.
It therefore appears important to avoid added infection in all patients admitted for urological operations, whether the urine is already infected or not.

Because of the wide variety of organisms which may cause blood-stream infection originating in the urinary tract, and because they may be resistant to several drugs, the initial treatment should include injections of two or more antibiotics, pending the identification of the causative strain.

Bladder Drainage for Acute Retention of Urine. - Many patients came to prostatectomy with established urinary infections which had usually started during previous catheter drainage or instrumentation, in these hospitals or elsewhere. Except for a few patients who were treated by immediate prostatectomy, the routine emergency treatment of acute retention was to drain the bladder by an open method, with an indwelling catheter and drainage tube which were freshly boiled before use.

A controlled trial was carried out in order to evaluate a simple method of closed drainage, the essential feature of which was that the end of the drainage tube was kept below the surface of formalin in a Winchester bottle (Miller et al., 1960). This maintained sterility of the urine in the bottle, and was a fluid trap to exclude air bubbles. When the bottle became full, the tube was clamped while it was transferred to a new bottle. If the patient left his bedside, he carried his bottle with him. The results are summarized in Table IV. Patients with open drainage quickly became infected, whereas most of those with closed drainage did not.

TABLE IV

URINARY INFECTION DURING CONTINUOUS BLADDER DRAINAGE FOR ACUTE RETENTION

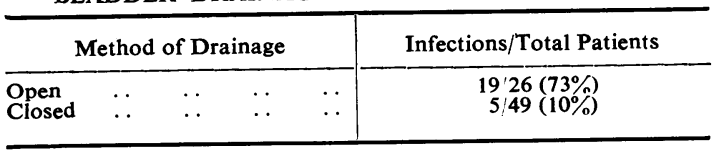

Gynaecological Operations.-Some operations for vaginal repair and vaginal hysterectomy necessitated drainage of the bladder by indwelling catheter for a few days afterwards. An open drainage method was used. Subsequently, during the remainder of the post-operative period, a catheter was passed when necessary to remove residual urine. The frequency of catheterization varied greatly from patient to patient. In a preliminary investigation, it was found that nearly all the patients developed well-marked urinary 
TABLE V

URINARY INFECTIONS AFTER GYNAECOLOGICAL OPERATIONS IN RELATION TO METHODS OF DRAINING THE BLADDER

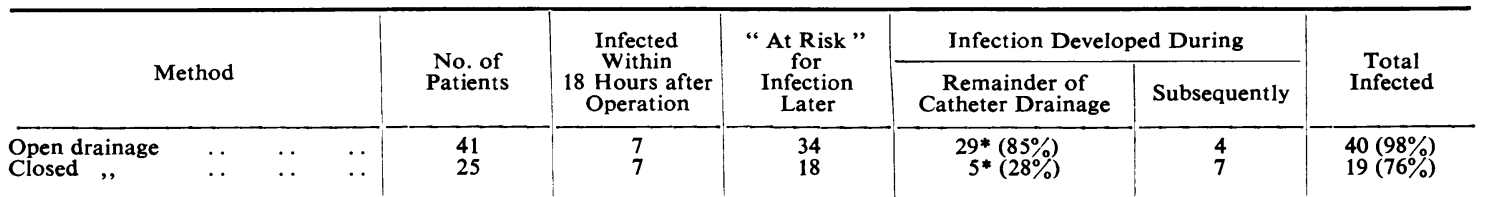

* $\chi^{2}$ (corrected) for the difference in the incidence of infection of patients on closed and open drainage during this period was $14 \cdot 75 ; P<0 \cdot 001$.

infections (Table II), often accompanied by clinical disturbance and sometimes requiring chemotherapy. Some (not included in this series) were given prophylactic antibiotics, an undesirable practice which, however, sometimes prevented infection.

From March 25, 1959, a controlled trial was carried out to compare the incidence of infection with closed and open drainage. Alternate patients in one ward were given bladder drainage by one or other method. While the indwelling catheter was in situ there were far fewer infections with closed drainage, except during the immediate postoperative period when the incidence was high in both groups (Table V). Most of the early postoperative infections were probably caused by organisms introduced by the passage of catheters before or during operation. After the removal of the drainage tube, the incidence of infection was again similar in the two groups, probably because of the intermittent catheterization to which both were subjected. Contamination of the catheters was not a likely cause of infection, since they were freshly boiled before use. It seemed probable that both the post-drainage infections and the immediate post-operative infections were caused by organisms lying in the urethra which were pushed into the bladder by catheterization. This conclusion was supported by a comparison of the streptomycin sensitivity of the coliform and proteus bacilli causing infection at different periods after operation (Table VI). Most of the infections during open drainage were caused by

\section{TABLE VI}

STREPTOMYCIN RESISTANCE OF COLIFORM AND PROTEUS BACILLI CAUSING URINARY INFECTION AFTER GYNAECOLOGICAL OPERATIONS

\begin{tabular}{|c|c|c|c|c|}
\hline & \multicolumn{2}{|c|}{$\begin{array}{l}\text { Streptomycin- } \\
\text { resistant }\end{array}$} & \multicolumn{2}{|c|}{$\begin{array}{l}\text { Streptomycin- } \\
\text { sensitive }\end{array}$} \\
\hline & $\underset{\text { Bacilli }}{\text { Coliform }}$ & Proteus & $\begin{array}{c}\text { Coliform } \\
\text { Bacilli }\end{array}$ & Proteus \\
\hline 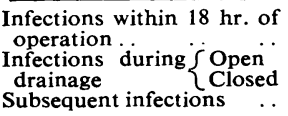 & $\begin{array}{r}0 \\
18 \\
0 \\
1\end{array}$ & $\begin{array}{r}0 \\
10 \\
0 \\
0\end{array}$ & $\begin{array}{l}6 \\
2 \\
3 \\
8\end{array}$ & $\begin{array}{l}3 \\
5 \\
1 \\
2\end{array}$ \\
\hline
\end{tabular}

streptomycin-resistant bacilli which probably came from the environment by cross-infection, whereas most of the other infections were caused by streptomycin-sensitive strains.

It is clear that closed drainage, though an important precaution, gave incomplete protection against infection. The passage of catheters after the drainage period should be kept to a minimum, and the procedure made as safe as possible when it has to be performed. Investigations are now in progress to determine whether the risk of infection can be reduced by instilling a disinfectant into the urethra before catheterization.

\section{Discussion}

There can be no doubt of the importance of avoiding urinary infection in all urological and gynaecological patients. In addition to the harm suffered by some of the patients, a high incidence of infection provides a temptation to employ a prophylactic antibiotic "cover" for operations ; and some of the infections require treatment with antibiotics. A reduction in the incidence of infection, therefore, should diminish the consumption of antibacterial drugs in the wards and hence the spread of antibiotic-resistant strains.

In addition to the acute complications which may follow post-operative urinary infections, there is also the possibility that some patients may progress to chronic pyelonephritis. It is particularly important, therefore, to avoid infection in the comparatively young women who come for gynaecological operations.

Even the simple passage of a catheter may infect the bladder in either sex. Clinical pathologists, therefore, should be prepared to report on "midstream "specimens of urine from women as well as men and only to ask for catheter specimens in exceptional circumstances.

The routes by which organisms may reach the bladder while it is being drained by an indwelling catheter have already been mentioned. The success of the closed method in preventing infection during simple drainage of the male bladder showed that the principal route of 
infection was the lumen of the catheter and drainage tube through which air bubbles readily ascend and carry up bacteria, unless steps are taken to prevent them. Infection in these patients can rarely if ever have been caused by organisms entering the bladder via the secretion which collects outside the catheter, as suggested by Kass and Schneiderman (1957). Kass and Sossen (1959) prevented infection by continuous irrigation with a weak solution of acetic acid, but this method would wash out bacteria from the bladder, no matter how they had entered it. However, the " extra-catheter" route may prove to be important in females and also in males whose bladders have to be drained for more than a week or so, which was the usual period of drainage after acute retention.

The proper disinfection of cystoscopes and resectoscopes was the simplest of all the precautions. Recent experience suggests that immersion for one or two minutes in a solution of chlorhexidine $0.5 \%$ in $70 \%$ alcohol (after thorough rinsing with water) may be as good as the slower method using aqueous chlorhexidine solution; but the margin of safety is small. The method of pasteurization described by Francis (1959) should be even better, and has the added advantage of killing tubercle bacilli.

The adoption of closed drainage had an important secondary effect in reducing the reservoirs of antibiotic-resistant bacteria which had often caused cross-infection. Formerly, bacteria had multiplied freely in the open vessels into which the urine was drained. Antibioticresistant strains, chiefly Klebsiellae, could frequently be found there in large numbers and must often have contaminated the hands of the nurses who emptied the vessels.

The risk of infection during catheter drainage is increased if the catheter has to be changed.
Rubber catheters often have to be changed after a week or so, because of non-bacterial inflammation of the urethra. Bladder drainage for long periods should therefore be affected by means of a non-irritating catheter such as the narrow-bore plastic catheter described by Gibbon (1958).

We are grateful to the Board of Governors of the United Bristol Hospitals for a grant which enabled us to do this work, to Professor G. G. Lennon for his encouragement, to the clinicians who allowed us to study their patients, and to the nursing staffs for their assistance. Our thanks are also due to Dr. F. J. W. Lewis and Dr. S. T. Crowther for their help, and to Mr. L. J. Waller for much support in the laboratory work.

\section{REFERENCES}

Dutton, A. A. C., and Ralston, M. (1957). Lancet, 1, 115. Ezzo, J. A., and Knight, W. A., Jr. (1957). A.M.A. Arch. intern.

Fairbrother, R. W. (1952). Association of Clinical Pathologists Broadsheet No. 1 .

Francis, A. E. (1959). Proc. roy. Soc. Med., 52, 998.

Gibbon, N. (1958). Brit. J. Urol., 30, 1

Gillespie, W. A. (1952). J. Path. Bact., 64, 551. (1956). Proc. roy. Soc. Med., 49, 1045 Alder, V. G., Ayliffe, G. A. J., Bradbeer, J. W., and Wypkema, W. (1959). Lancet, 2, 781 .

Grey, D. N. (1955). J. Urol. (Baltimore), 73, 709.

Hall, W. H., and Gold, D. (1955). A.M.A. Arch. intern. Med., 96, 403. Hall, W. H., and Gold, D. (1955). A.M.A. Arch. intern. Med., 96, 40

Harper, G. J., and Cawston, W. C. (1945). J. Path. Bact., 57, 59.

Kass, E. H. (1956). Trans, Ass. Amer. Phycns, 69, 56. and Schneiderman, L. J. (1957). New Engl. J. Med., $256,556$. and Sossen, H.S. (1959). J. Amer. med. Ass., 169, 1181.

Lattimer, J. K., Seneca, H., Zinsser, H. H., and Troc, O. (1959) J. Amer. med. Ass., 170,938.

Linton, K. B. (1960). J. clin. Path., 13, 168.

Miller, A., Gillespie, W. A., Linton, K. B., Slade, N., and Mitchell, J.'P. (1958). Lancet, 2, 608. Linton, K. B., Gillespie, W. A., Slade, N., and Mitchell, J. P. (1960). Ibid., 1, 310.

Grsk (1952). Acta path. microbiol. scand., Suppl. 93, 259. (1954). Ibid., 35, 194 .

Sanford, J. P., Favour, C. B., Mao, F. H., and Harrison, J. H. (1956). Amer. J. Med., 20, 88

Scott, W. W. (1929). J. Urol. (Baltimore), 21,527

Shackman, R., and Messent, D. (1954). Brit. med. J., 2, 1009

Shackman, R., and Proc. roy. Soc. Med., 51, 331.

Spittel. J A J Martin, W.J., and Nichols, D. R. (1956). Ann.intern. Med., 44, 302 .

Talbot, J. M., Cunliffe, A. C., and Gower, N. D. (1957). J. clin. Path. $10,222$.

Waisbren, B. A. (1951). A.M.A. Arch. intern. Med., 88, 467.

Williams, R. E. O., and Rippon, J. E. (1952). J. Hyg. (Lond.), 50, 320. 